Herz $2020 \cdot 45: 726-738$

https://doi.org/10.1007/s00059-019-04850-w

Received: 6 March 2019

Revised: 11 August 2019

Accepted: 13 August 2019

Published online: 25 September 2019

(c) The Author(s) 2019

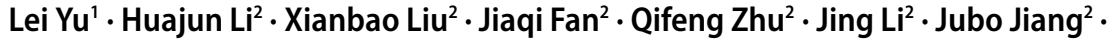
Jian'an Wang ${ }^{2,3}$

' Department of Ultrasonography, The First Affiliated Hospital, Zhejiang University School of Medicine, Hangzhou, China

${ }^{2}$ Department of Cardiology, Second Affiliated Hospital, Zhejiang University School of Medicine, Hangzhou, China

${ }^{3}$ Zhejiang University School of Medicine, Hangzhou, China

\title{
Left ventricular remodeling and dysfunction in obstructive sleep apnea
}

\section{Systematic review and meta-analysis}

\section{Electronic supplementary material}

The online version of this article (https://doi. org/10.1007/s00059-019-04850-w) contains supplementary material, which is available to authorized users.

Obstructive sleep apnea syndrome (OSAS) is a common chronic disorder characterized by recurrent episodes of upper respiratory tract obstruction and hypoxia during sleep, leading to the occurrence of loud snoring, breathing interruptions, frequent awakenings or insomnia, morning fatigue, daytime sleepiness, attention deficit, and cognitive dysfunction[18]. The diagnosis and severity of OSAS are usually assessed by the total number of apnea and hypopnea episodes per hour of sleep, namely, the apnea hypopnea index (AHI). This condition is highly prevalent in the general population, affecting $2 \%-15 \%$ of adults [7, 20, 21, 23, 44, 56, 57], particularly those older than 65 years.

Obstructive sleep apnea syndrome is not only associated with a higher risk of occupational accidents but also leads to more cardiovascular diseases such as cardiac remodeling and dysfunction [7, 41]. Echocardiography is a noninvasive, low-cost, time-saving and accurate tool for assessing alterations in cardiac structure and function, and has been widely used in the clinic. To date, there have been some studies exploring the alternations in echocardiographic parameters in OSAS patients. However, large-scale clinical controlled trials on this field are still lacking, and most of the related research had small sample sizes and used inconsistent inclusion and exclusion criteria.

Owing to the overall low awareness of the relationship between OSAS and left ventricular (LV) dysfunction in clinical management, the aim of the current study was to summarize the association between OSAS and LV function and structure, in order to provide guidelines for clinical decision-making.

\section{Methods}

\section{Data source, search strategy, and selection criteria}

Electronic databases including PubMed, Embase, and the Cochrane Library were searched from database inception to March 2018 using the following terms: "ventricular function, left"; "ventricular dysfunction, left"; "heart failure"; "echocardiography"; "sleep apnea, obstructive"; and "sleep-disordered breathing” (see Supplementary Table S1). In addition, we also checked the reference lists of identified reports for other potentially relevant studies. The literature search and study selection were undertaken by two reviewers independently.
Any inconsistencies were settled by another researcher. A systematic review was conducted in accordance with the Preferred Reporting Items for Systematic Reviews and Meta-Analyses (PRISMA).

The following criteria were used to identify potentially suitable studies: (1) articles were written fully in English; (2) enrolled participants were all adults (older than 18 years); (3) OSAS was diagnosed by polysomnography and assessed with the AHI; (4) the study included a control group; (5) the study reported at least one of the measures of LV function or structure; (6) there was no significant difference in the body mass index (BMI) of the two groups.

The exclusion criteria were: (1) duplicate reports; (2) studies that had not yet terminated; (3) reviews, case reports, or animal experiments; (4) central sleep apnea; (5) OSAS patients with major comorbidities such as structural heart disease, cardiomyopathy, obstructive or restrictive lung disease demonstrated on pulmonary function testing, pulmonary hypertension, etc.; (6) previous or current treatment for OSAS; (7) studies with hypertension in OSAS group or in control group were excluded in order to avoid the definite effect of hypertension or antihypertension drugs on cardiac remodeling (as an exception, one article was included because the blood pressure level and antihypertensive drugs were both matched 
758 relevant studies found using MeSH terms in PubMed, Embase and Cochrane

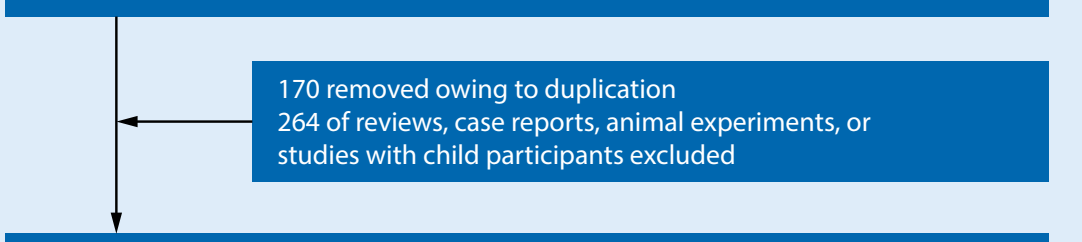

324 studies retrieved for more detailed assessment

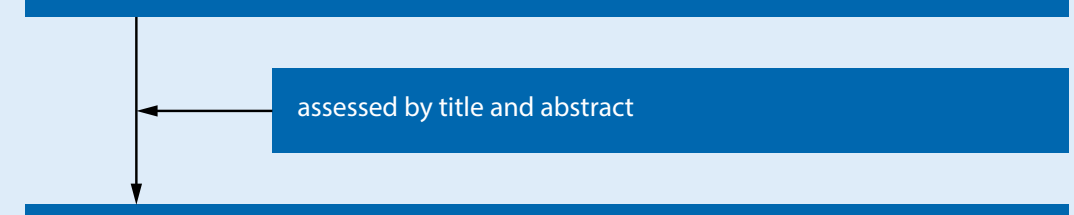

189 studies potentially appropriate for analysis

Inclusion criteria:

(1) articles were written fully in English;

(2) enrolled participants were all adults;

(3) OSAS was diagnosecl by polysomnography and

assessed by apnea-hypopnea index;

(4) the study included a control group

(5) the study reported at least one of the measures of

left cardiac function or remodeling;

(6) BMI of OSAS and control group not significantly different.

Other exclusion criteria:

(1) OSAS patients with major comorbidities;

(2) central sleep apnea

(3) previous or current treatment for OSA.

17 studies finally included in the main analysis

Fig. 1 Study selection. BMI body mass index, OSAS obstructive sleep apnea syndrome

between the control group and OSAS group).

\section{Data extraction and synthesis}

Two independent readers screened and extracted data from eligible articles. The following data were extracted from the relevant studies: first author, year of publication, country, number of participants, mean age, BMI, mean AHI, OSAS diagnostic criteria, and LV morphology and function parameters. The main echocardiographic parameters included early diastolic peak flow velocity (E), late diastolic peak flow velocity $(\mathrm{A})$, deceleration
Several studies stratified patients on the basis of OSAS severity (mild, moderate, or severe) and reported the grouped LV function data within each stratum. The two formulae presented here were used to combine subgroups and calculate the overall means and standard deviations. However, in the subgroup analysis, each stratum was considered as a separate substudy.

The equations are listed in Supplementary Table S2.

Cochran's $\chi^{2}$ test and the $I^{2}$ statistic were applied to estimate the percentage of variability across studies due to between-study heterogeneity. Heterogeneity was considered statistically significant at $p<0.10$ and $I^{2}>50 \%$. The weighted mean difference (WMD) with 95\% confidence intervals (CIs) was calculated using a fixed-effects model if $I^{2}<50 \%$ and using a random-effects model if $I^{2}>50 \%$. Fisher's $z$ test was used to determine the statistical significance of the pooled WMDs. We conducted sensitivity analyses or subgroup analysis if $I^{2}>50 \%$. Egger's test and Begg's test were used to examine the presence of publication bias. All analyses were performed using the statistical package Stata, version 14.0 (StataCorp., College Station, TX, USA). The quality of the enrolled studies was evaluated by two independent reviewers according to the Newcastle-Ottawa Scale ranging from 0 to 8 .

\section{Results}

\section{Search results}

After a strict screening, 739 citations were removed according to the inclusion and exclusion criteria described earlier, and a total of 17 studies with 747 OSAS patients and 426 control participants were included in the final meta-analysis (see - Fig. 1).

\section{Characteristics of studies}

The publication years of the eligible studies ranged from 2005 to 2016. The majority of the studies (nine studies, 52.9\%) were conducted in Turkey; two studies were conducted in China, two were conducted in Spain, two were conducted in South Korea, one study was 
Herz 2020 · 45:726-738 https://doi.org/10.1007/s00059-019-04850-w

(c) The Author(s) 2019

L. Yu · H. Li · X. Liu · J. Fan · Q. Zhu · J. Li · J. Jiang · J. Wang

\section{Left ventricular remodeling and dysfunction in obstructive sleep apnea. Systematic review and meta- analysis}

\section{Abstract}

Background. Obstructive sleep apnea syndrome (OSAS) is associated with cardiovascular mortality and morbidity. Several studies have reported that it affects the left ventricle; however, large randomized controlled trials are lacking. The current study aimed to summarize the association between OSAS and left ventricular (LV) structure and function. Methods. Electronic databases (PubMed, Embase, and Cochrane) and references were searched for articles published until March 2018. A systematic review and metaanalysis were performed to assess LV structure and function in OSAS patients based on echocardiography.
Results. In total, 17 studies with 747 OSAS patients and 426 control participants were included. Patients with OSAS showed an increase in LV diastolic diameter (weighted mean difference [WMD], 95\% Cl: $1.24[0.68,1.80]$; $p<0.001$ ), LV systolic diameter (WMD, 95\% Cl: $1.14[0.47,1.81] ; p=0.001)$, and LV mass (WMD, 95\% Cl: 35.34 [20.67, 50.00]; $p<0.001$ ). In addition, left ventricular ejection fraction (LVEF) significantly decreased in the OSAS group compared with the controls (WMD, 95\% Cls: -1.82 [-2.76, -0.87$] ; p<0.001)$, and the reduction in LVEF was consistent with the severity of OSAS. The OSAS group also showed an increase in left atrial diameter (WMD, 95\%
Cl: 2.13 [1.48, 2.77]; $p<0.001)$ and left atrial diameter volume index (WMD, 95\% Cls: 3.96 $[3.32,4.61] ; p<0.001)$.

Conclusion. Obstructive sleep apnea syndrome leads to atrial dilatation, left ventricular hypertrophy, enlargement, mass increase and reduction of systolic function. Treatments for OSAS might be beneficial for the preservation of left cardiac structure and function.

Keywords Left ventricular hypertrophy - Cardiac remodeling - Left ventricular ejection fraction . Hypoxia - Echocardiography

\section{Remodeling und Dysfunktion linksventrikulär bei obstruktiver Schlafapnoe. Systematische Übersichtsarbeit und Metaanalyse}

\section{Zusammenfassung}

Hintergrund. Das obstruktive Schlafapnoesyndrom (OSAS) geht mit kardiovaskulärer Mortalität und Morbidität einher. Im Rahmen verschiedener Studien wurde berichtet, dass es sich auf den linken Ventrikel auswirkt; allerdings fehlen bisher große randomisierte kontrollierte Studien. Die aktuelle Studie zielte darauf ab, eine zusammenfassende Übersicht über den Zusammenhang zwischen OSAS und linksventrikulärer Struktur und Funktion zu geben.

Methoden. Elektronische Datenbanken (PubMed, Embase und Cochrane) sowie Literaturangaben wurden nach Artikeln durchsucht, die bis März 2018 publiziert worden waren. Dann wurden eine systematische Übersicht und eine Metaanalyse erstellt, um die LVStruktur und Funktion bei Patienten mit OSAS auf der Grundlage der Echokardiographie zu untersuchen.

Ergebnisse. Insgesamt wurden 17 Studien mit 747 OSAS-Patienten und 426 Kontrollen in die Studie einbezogen. Patienten mit OSAS zeigten einen Anstieg des diastolischen Durchmessers des LV (gewichtete mittlere Differenz, WMD: 1,24; $95 \%-\mathrm{Kl}, 95 \%$ KI: $0,68-1,80 ; p<0,001)$, des systolischen Durchmessers des LV (WMD: 1,14; $95 \%$ KI: $0,47-1,81 ; p=0,001)$ und der LV-Masse (WMD: 35,34; $95 \%$-KI: 20,67-50,00; $p<0,001$ ). Außerdem nahm die linksventrikuläre Ejektionsfraktion (LVEF) signifikant in der OSAS-Gruppe im Vergleich zu den Kontrollen ab (WMD: -1,82; $95 \%-K l:-2,76$ bis $-0,87$; $p<0,001)$, und die Abnahme der LVEF stand in Übereinstimmung mit dem Schweregrad des
OSAS. In der OSAS-Gruppe zeigte sich auch ein Anstieg des linksatrialen Durchmessers (WMD: 2,13; $95 \%-\mathrm{Kl}: 1,48-2,77 ; p<0,001)$ und des Volumenindex des linksatrialen Durchmessers (WMD: 3,96; 95 \%-Kl: 3,32-4,61; $p<0,001$ ). Schlussfolgerung. Ein obstruktives Schlafapnoesyndrom führt zur Vorhofdilatation, linksventrikulären Hypertrophie, Vergrößerung, Massenzunahme und Abnahme der systolischen Funktion. Die Behandlung eines OSAS könnte sich günstig auf den Erhalt der Linksherzstruktur und -funktion auswirken.

\section{Schlüsselwörter}

Linksventrikuläre Hypertrophie · Kardiales Remodeling - Linksventrikuläre Ejektionsfraktion. Hypoxie - Echokardiographie conducted in the United States, and one in Italy. In all studies, OSAS was diagnosed and assessed by polysomnography: The control group was defined as having $\mathrm{AHI}<5$ events $/ \mathrm{h}$, while mild, moderate, and severe OSAS were rated as, respectively, $5 \leq \mathrm{AHI}<15$ events $/ \mathrm{h}$, $15 \leq \mathrm{AHI}<30$ events $/ \mathrm{h}$, and $\mathrm{AHI} \geq 30$ events/h. For the assessment of left atrial (LA) remodeling, seven studies (41.2\%) used LAD and four studies (23.5\%) used LAVI. For the assessment of LV remodeling, 13 studies (76.4\%) used LVEDD, 11 studies (64.7\%) used LVESD, and six studies (35.3\%) used LVM. For the assessment of LV function, 15 studies (88.2\%) used LVEF. The main characteristics of the studies in this systematic review are listed in $\bullet$ Table 1 and the quality of included studies are listed in Supplementary Table S3.

\section{Meta-analysis}

- Table 2 summarizes the data for all the parameters of LA structure, LV structure, and LV function determined by the meta-analysis. Heterogeneity was obvious in the assessment of several parameters, which was speculated as a result of the inconsistent degree of severity of OSAS, varied ages of participants, BMI, geographical location, and duration of OSAS. 


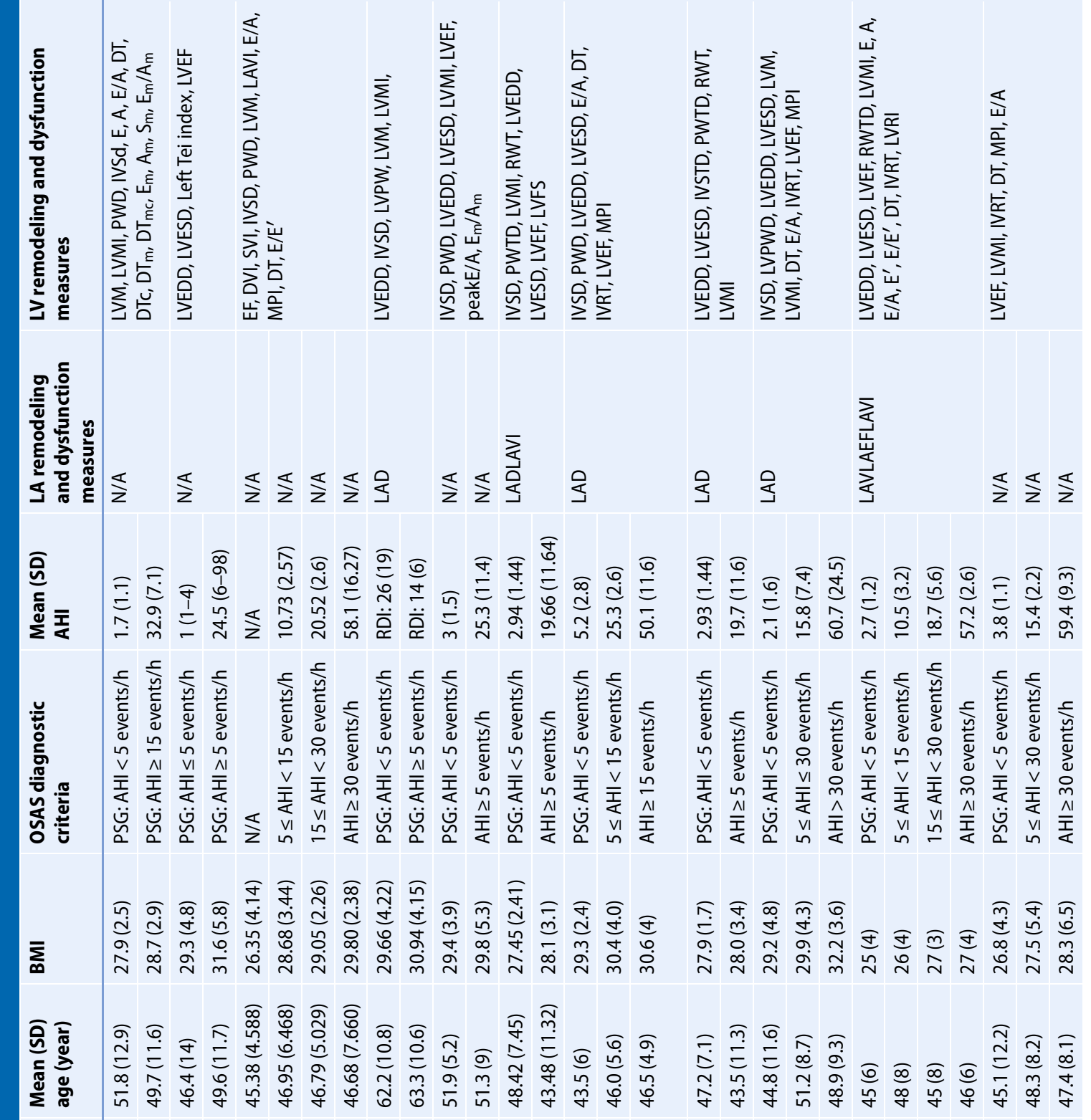

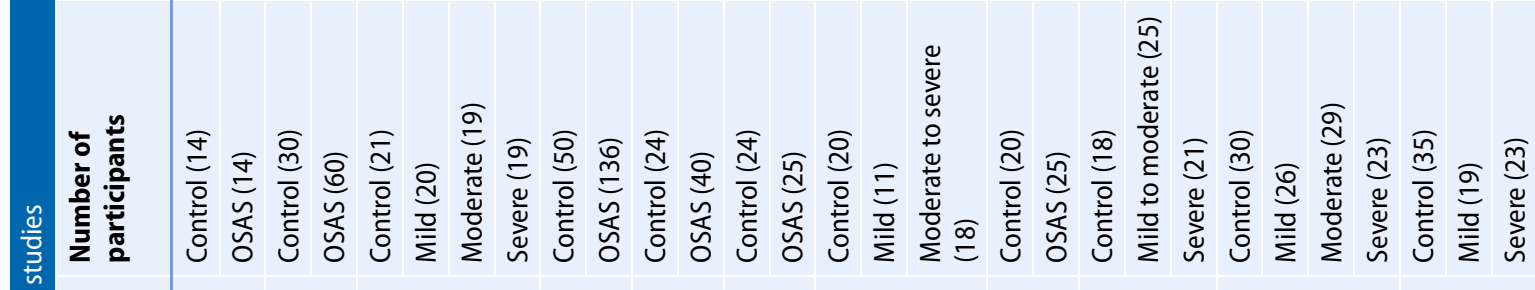

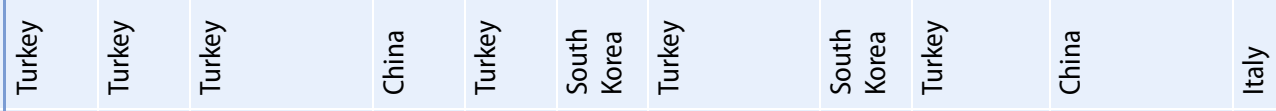

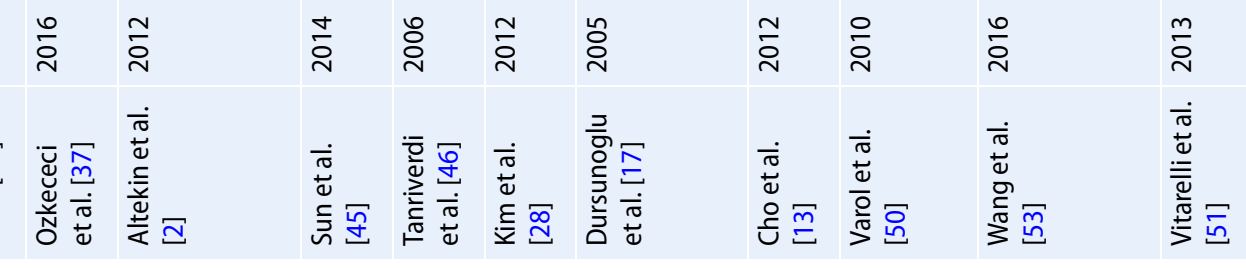




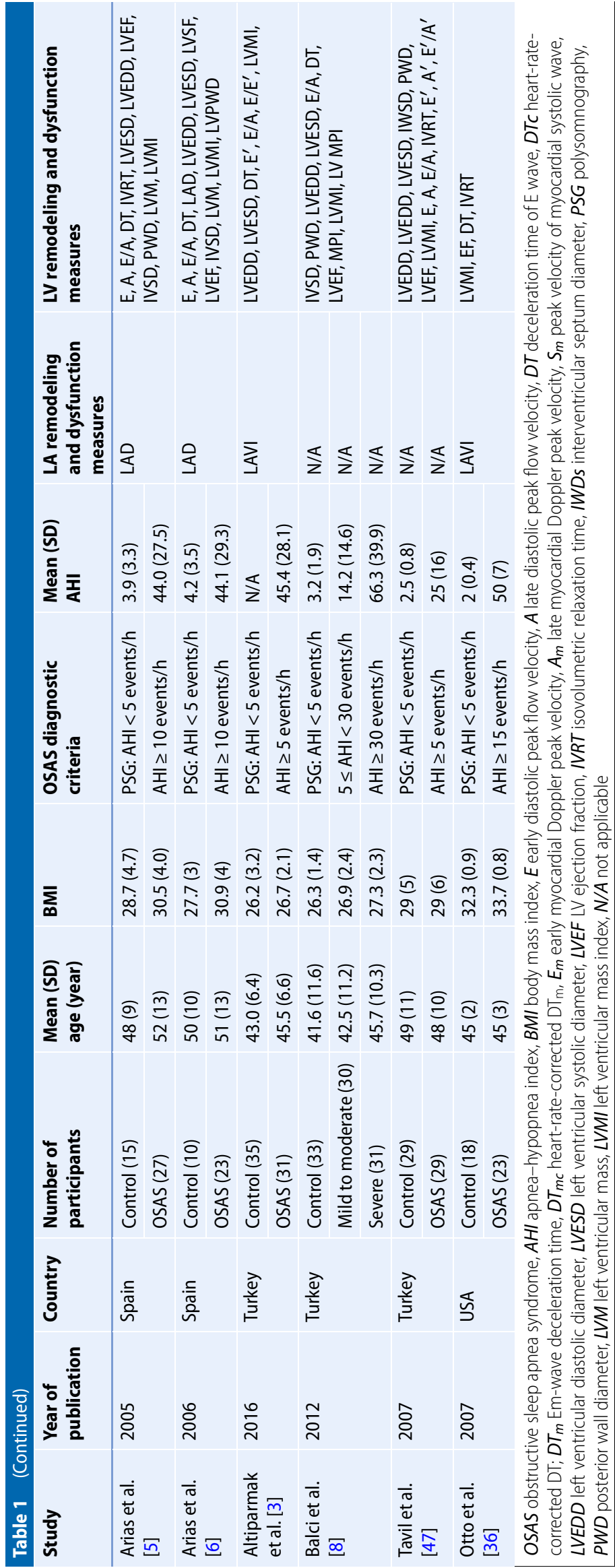

\section{Left ventricular structure}

The parameters LVEDD, LVESD, and LVM were used to assess LV structure.

Differences in LVEDD were reported in 13 studies involving 563 OSAS patients and 319 control participants. The metaanalysis showed that the LVEDD in patients with OSAS was significantly higher compared with the controls (WMD [95\% CIs]: $1.24[0.68,1.80] ; p<0.001$; nonsignificant heterogeneity; - Fig. 2). In addition, differences in LVESD were reported in 11 studies involving 396 OSAS patients and 243 control participants, which showed that patients with OSAS also had significantly increased LVESD compared with the controls (WMD [95\% CIs]: 1.14 [0.47, 1.81]; $p=0.001$; nonsignificant heterogeneity; - Fig. 3 ). The subgroup analysis was not performed owing to the limited number of studies with OSAS stratification.

Differences in LVM were reported in six studies involving 304 OSAS patients and 128 control participants. The metaanalysis demonstrated that the LVM (WMD [95\% CIs]: 35.34 [20.67, 50.00]; $p<0.001$; - Fig. 4) was significantly elevated compared with the controls. However, potential evidence of significant heterogeneity was detected, and thus sensitivity analysis was conducted. After exclusion of each study from the pooled analysis, the WMDs were always $>0$, which confirmed the reliability of these results (• Fig. 5).

\section{Left ventricular function}

Left ventricular ejection fraction was used to assess LV systolic function and LV diastolic function. Differences in LVEF were reported in 15 studies involving 710 OSAS patients and 394 control participants. The LVEF in patients with OSAS decreased significantly compared with the controls (WMD [95\% CIs]: $-3.01[-1.90,-0.79] ; p<0.001$; $\bullet$ Fig. 6 ).

Further subgroup analysis indicated that the reduction in LVEF was consistent with the severity of OSAS ( $\bullet$ Fig. 7).

Significant heterogeneity was detected in the analysis of LVEF. However, sensitivity analysis showed that after exclusion of each study from the pooled analysis, the results were reliable ( $\bullet$ Fig. 8). 


\begin{tabular}{|c|c|c|c|c|c|c|c|c|c|}
\hline \multirow{2}{*}{$\begin{array}{l}\text { Echocardiographic } \\
\text { parameters }\end{array}$} & \multirow{2}{*}{$\begin{array}{l}\text { Number of } \\
\text { studies }\end{array}$} & \multirow{2}{*}{$\begin{array}{l}\text { OSAS/ } \\
\text { control }\end{array}$} & \multirow[t]{2}{*}{ WMD $(95 \% \mathrm{Cl})$} & \multirow[t]{2}{*}{$p$} & \multicolumn{3}{|c|}{ Study heterogeneity } & \multirow{2}{*}{$\begin{array}{l}\text { Egger's } \\
\text { test } p\end{array}$} & \multirow{2}{*}{$\begin{array}{l}\text { Begg's } \\
\text { test } p\end{array}$} \\
\hline & & & & & $I^{2}(\%)$ & $x^{2}$ & $p$ & & \\
\hline $\operatorname{LVEDD}(\mathrm{mm})$ & 13 & $563 / 319$ & $1.24(0.68,1.80)$ & $<0.001$ & 0.0 & 9.52 & 0.658 & 0.431 & 0.951 \\
\hline $\operatorname{LVESD}(\mathrm{mm})$ & 11 & $396 / 234$ & $1.14(0.47,1.81)$ & 0.001 & 0.0 & 7.31 & 0.696 & 0.722 & 1.00 \\
\hline LVM & 6 & $304 / 128$ & $35.34(20.67,50.00)$ & $<0.001$ & 79.1 & 66.05 & $<0.001$ & 0.914 & 0.917 \\
\hline LVEF (\%) & 15 & $710 / 394$ & $-3.01(-1.90,-0.79)$ & 0.001 & 64.7 & 39.72 & $<0.001$ & 0.048 & 0.038 \\
\hline LAD & 7 & $311 / 157$ & $2.13(1.48,2.77)$ & $<0.001$ & 2.2 & 6.13 & 0.408 & 0.072 & 0.05 \\
\hline LAVI & 3 & $159 / 69$ & $3.96(3.32,4.61)$ & $<0.001$ & 0.0 & 1.62 & 0.445 & 0.735 & 1.000 \\
\hline
\end{tabular}

OSAS obstructive sleep apnea syndrome, LVEDD left ventricular diastolic diameter, LVESD left ventricular systolic diameter, LVM left ventricular mass, $L V M I$ left ventricular mass index, LVEF LV ejection fraction, $E$ early diastolic peak flow velocity, $A$ late diastolic peak flow velocity, $C I$ confidence interval

\section{Left atrial structure}

The parameters LAD and LAV were used to evaluate LA structure.

Differences in LAD were reported in seven studies involving 311 OSAS patients and 157 control participants. The meta-analysis showed that the LAD in patients with OSAS was significantly higher than in the control group (WMD [95\% CIs]: 2.13 [1.48, 2.77]; $p<0.001$; nonsignificant heterogeneity; - Fig. 9). The LAVI was also compared through an analysis of four studies comprising 184 OSAS patients and 93 control participants. Owing to apparent heterogeneity, sensitivity analysis was conducted and one study was accordingly removed. The three studies finally selected involving 159 OSAS patients and 69 control participants showed that patients with OSAS also had significantly increased LAVI compared with the controls (WMD [95\% CIs]: 3.96 [3.32, 4.61]; $p<0.001$; nonsignificant heterogeneity; - Fig. 10). Neither subgroup analysis of the LAD nor of the LAVI was performed because of the limited number of studies with OSAS stratification.

\section{Discussion}

\section{Main findings}

To our knowledge, this is the first meta-analysis to systematically evaluate changes in left cardiac structure and function in OSAS patients. Particularly, the effect of systemic hypertension was eliminated in the current analysis by excluding those studies with hypertensive patients enrolled, since many ultrasonic parameters may be affected by hypertension. Thus, we demonstrate that OSAS induces cardiac abnormality independent of systemic hypertension. Finally, 17 case-control studies were included in this meta-analysis with a total of 747 patients with OSAS and 426 controls.

We found that alterations in the echocardiographic parameters of LV and LA remodeling, including an increase in LVEDD, LVESD, LVM, LAD, and LAVI, were important features in OSA patients without major comorbidities, which indicated that OSAS resulted in enlargement and hypertrophy of the left ventricle and atrium. Moreover, significant decreases in LVEF were observed in OSAS patients. It should be noted that the alterations in LVEF seemed not to be remarkable enough to induce obvious clinical symptoms of LV dysfunction.

In the analysis of LVEF, we found significant heterogeneity between studies. The heterogeneity is to be expected given the variation in disease severity. However, subgroup analysis still showed significant heterogeneity, which may stem from the variety of studies conducted by different teams at various geographic locations as well as the differences in the patient populations.

\section{LV remodeling and dysfunction in OSAS patients}

It has been reported that intermittent hypoxia could induce LV remodeling, which was regarded as the basis of LV dysfunction caused by OSAS [15]. Although the negative effect of intermittent hypoxia on the cardiovascular system has not been completely clarified, multiple putative mechanisms including sympathetic overactivation, oxidative stress, in- flammation, metabolic deregulation, and endothelial dysfunction have been suggested to be involved.

Hypoxemia, hypercapnia, and acidosis, induced by chronic intermittent hypoxia in OSAS patients, could activate the sympathetic nervous system. Prior studies showed that patients with metabolic syndrome and comorbid OSAS have a higher sympathetic drive than do patients with metabolic syndrome without OSAS [22, 49]. Furthermore, Scala et al. reported a significant correlation between OSAS and cardiac adrenergic impairment in patients with heart failure [43]. The exposure to intermittent hypoxia and hypercapnia, elicited by OSAS, increases muscle sympathetic nerve activity (MSNA) acutely during sleep [10], and the over-activation of the sympathetic nervous system is persistent even after removal of the hypoxic stimulus [4, 54]. Bradley et al. reported that LV transmural pressure was increased in response to the generation of negative intrathoracic pressure (Pit) and the elevation of systemic blood pressure secondary to hypoxia-induced sympathetic nervous system activation [11]. This results in the reduction of LV preload and increased afterload, which can directly affect LV systolic function [26]. The combination of increased LF afterload and increased heart rate (HR) promotes myocardial oxygen demand, thus brings a higher risk of cardiac ischemia and arrhythmias, and chronically contributes to LV hypertrophy and failure. It is well known that the sympathetic nervous system is the most prominent among neurohormonal mechanisms in HF, which pushes the heart to work at an overloaded level, 


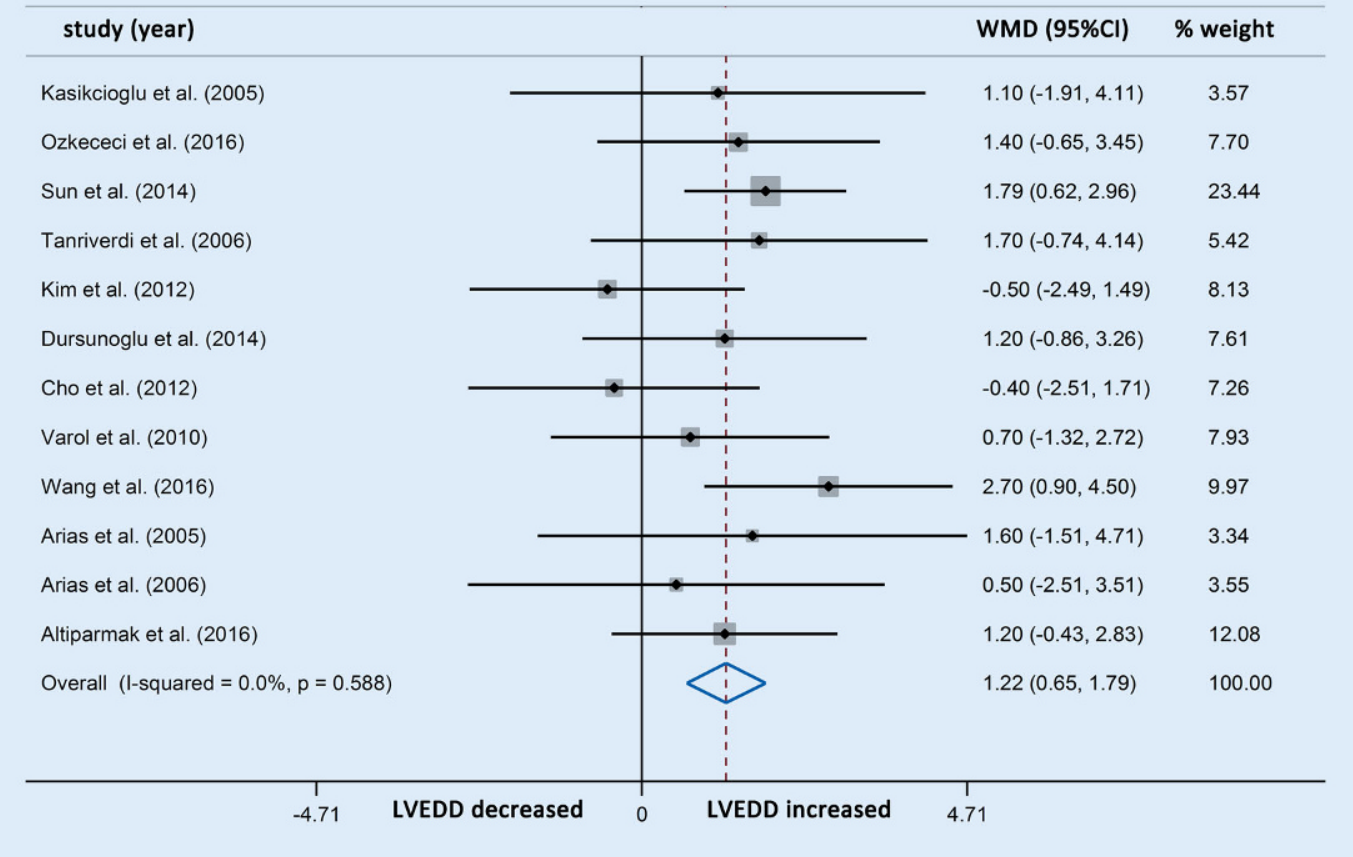

Fig. $2 \triangleleft$ Forest plot of the differences in left ventricular end diastolic diameter (LVEDD) between the patients with obstructive sleep apnea syndrome and healthy controls based on echocardiography. WMD weighted mean difference

\begin{tabular}{|c|c|c|c|}
\hline study (year) & & WMD $(95 \% \mathrm{Cl})$ & $\%$ weight \\
\hline Kasikcioglu et al. (2005) & & $1.30(-0.93,3.53)$ & 9.01 \\
\hline Ozkececi et al. (2016) & $\rightarrow$ & $2.10(0.46,3.74)$ & 16.78 \\
\hline Tanriverdi et al. (2006) & $\rightarrow-$ & $2.20(0.02,4.38)$ & 9.41 \\
\hline Kim et al. (2012) & & $-0.40(-2.43,1.63)$ & 10.90 \\
\hline Dursunoglu et al. (2014) & & $1.28(-1.66,4.22)$ & 5.18 \\
\hline Cho et al. (2012) & & $-0.10(-2.05,1.85)$ & 11.87 \\
\hline Varol et al. (2010) & & $0.60(-1.26,2.46)$ & 13.06 \\
\hline Wang et al. (2016) & & $0.94(-2.64,4.52)$ & 3.50 \\
\hline Arias et al. (2005) & & $2.30(-0.31,4.91)$ & 6.62 \\
\hline Arias et al. (2006) & & $1.80(-1.23,4.83)$ & 4.90 \\
\hline Tavil et al. (2007) & & $1.20(-1.06,3.46)$ & 8.77 \\
\hline Overall (I-squared $=0.0 \%, p=0.696)$ & & $1.14(0.47,1.81)$ & 100.00 \\
\hline LVESD decreased & LVESD increased & $\begin{array}{l}1 \\
4.91\end{array}$ & \\
\hline
\end{tabular}

Fig. $3<$ Forest plot of the differences in left ventricular end-systolic diameter (LVESD) between the patients with obstructive sleep apnea syndrome and healthy controls based on echocardiography. WMD weighted mean difference and confers significant toxicity to the failing heart and increases morbidity and mortality in chronic decompensated HF [32].

In addition, systemic inflammation triggered by OSAS plays an important role in intermittent hypoxia-induced LV remodeling, as was confirmed by elevated plasma levels of tumor necrosis factoralpha (TNF- $\alpha$ ) and interleukin-6 (IL-6) in patients with OSA [34]. Inflammatory response and free radical generation could cause an imbalance between myocardial oxidation and antioxidant activity, result in myocardial injury, and increase susceptibility to myocardial ischemia [19]. The consequent myocardial ischemia leads to a shortage in ATP production, inorganic phosphate accumulation, and myocardial acidosis, which inhibit excitement-contraction coupling and cause regional ventricular systolic dysfunction [40]. Besides, in the case of OSAS, exposure to intermittent hypoxia elevates blood pressure, and thus may induce functional, mechanical, and structural changes in the aortic wall in response to hemodynamic and biomechanical stress, which has been verified in mice [12]. Hypoxia stimulates the elastic 


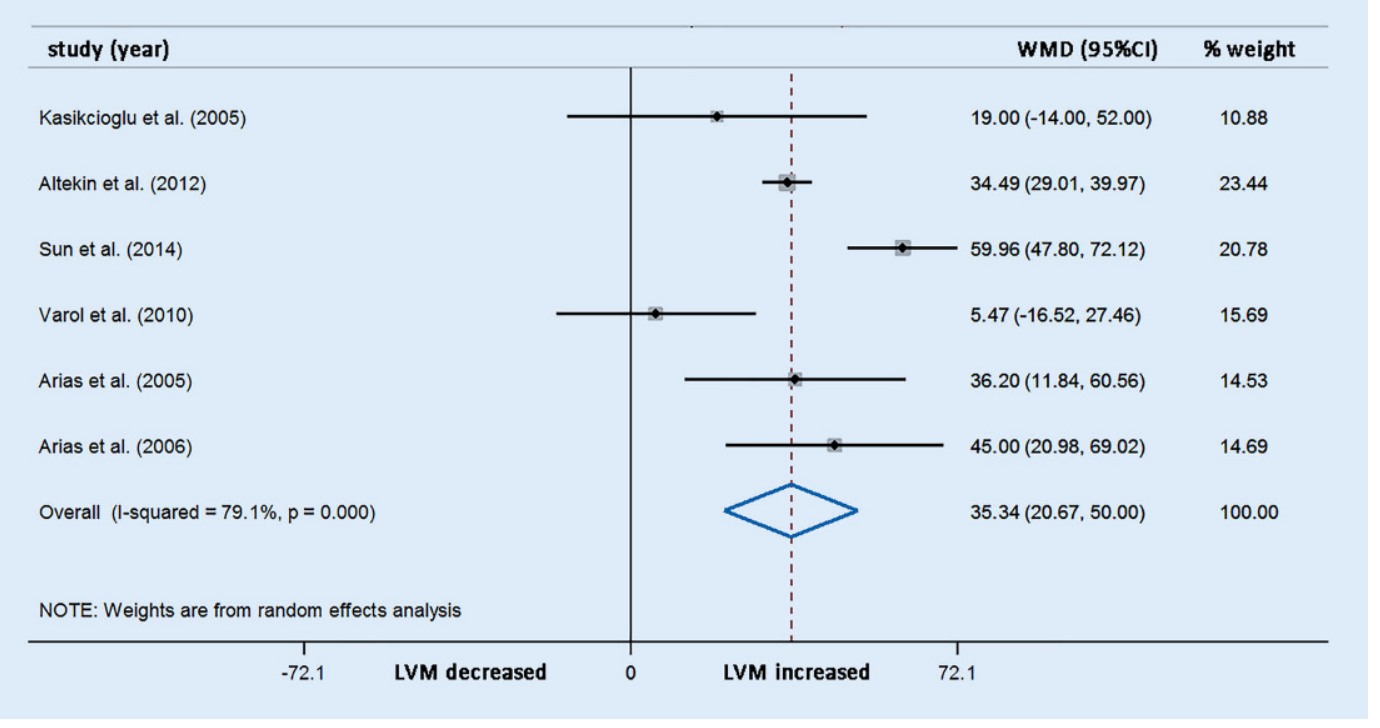

Fig. $4 \triangleleft$ Forest plot of the differences in left ventricular mass (LVM) between patients with obstructive sleep apnea syndrome patients and healthy controls based on echocardiography. WMD weighted mean difference

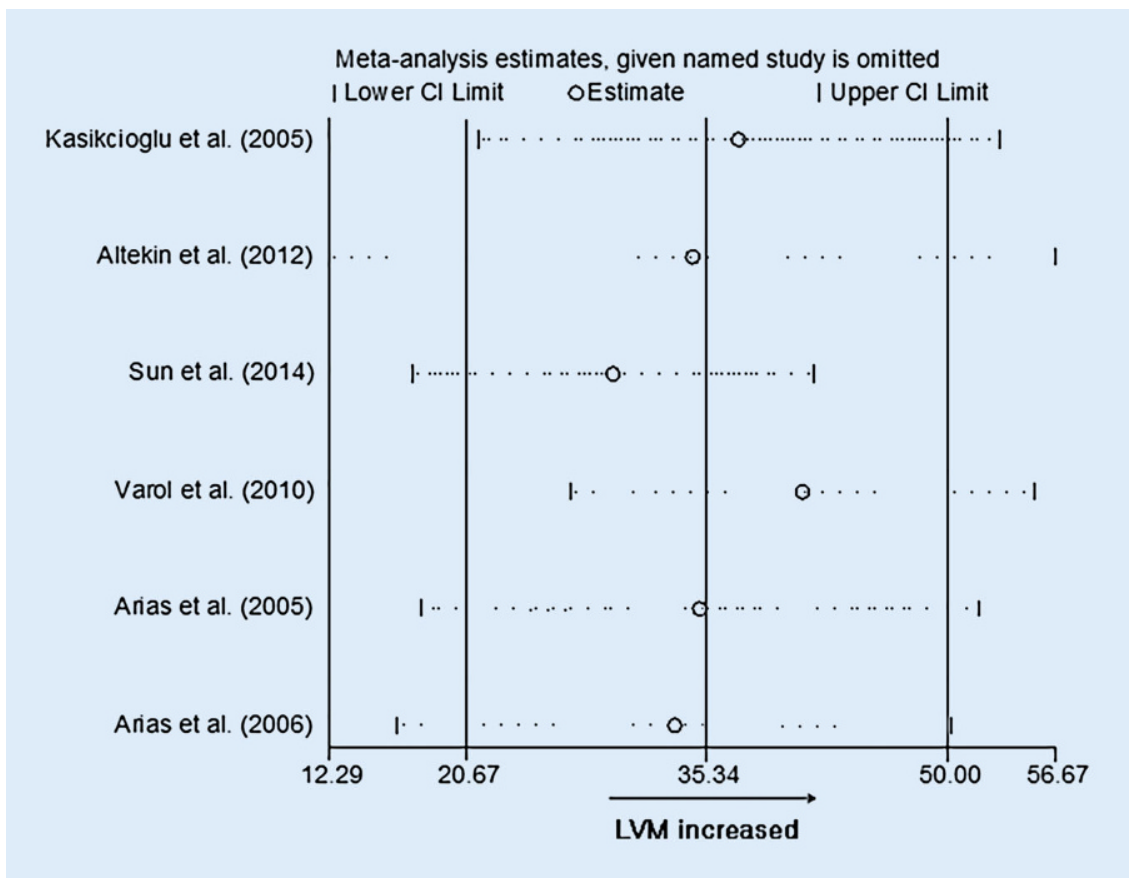

Fig. $5 \Delta$ Sensitivity analyses of left ventricular mass (LVM). Cl confidence interval

fiber network with disorganization, fragmentation, and estrangement between the endpoints of disrupted fibers, and induces collagen and mucoid interlaminar accumulation in the extracellular matrix as well as LF perivascular fibrosis. These cardiovascular remodeling events induced by hypoxia were normalized after continuous positive airway pressure (CPAP) treatment.

The hemodynamic changes associated with obesity might contribute to the increased LV mass observed in pa- tients with OSA. Of interest, Parisi et al. have pointed out that HF patients with sleep disordered-breathing have higher epicardial adipose tissue (EAT) thickness values than do HF patients without nocturnal apneas [39], which indicates EAT might be a pathophysiological link between OSAS and increased cardiovascular risk $[31,33]$. Besides, CPAP therapy reduces EAT and significantly ameliorates cardiometabolic parameters in obese OSAS patients [29]. Moreover, EAT is a source of several adipocytokines and directly affects the myocardium through vasocrine and paracrine mechanisms [24]. Exposure to hypoxia leads to higher production of factor-1a and Fos-like antigen (FOSL) 2, resulting in up-regulation of leptin expression in the EAT, along with increased vascularization, inflammation, and fibrosis [16]. It has been demonstrated that EAT thickness has a high correlation with sympathetic nervous system hyperactivity and it is a local source of catecholamines in HF patients, which suggests sympathetic nervous system hyperactivity is a potential pathophysiological link between sleep apneas and EAT in HF [38].

Overall, increased sympathetic activity, endothelial dysfunction, systemic inflammation, oxidative stress, and metabolic anomalies induced by intermittent hypoxia play major roles in the progression of LV remodeling and dysfunction.

\section{LA remodeling in OSAS patients}

Our analysis revealed a significant increase in LA volume in patients with OSAS. Left atrial enlargement was considered to occur owing to elevated LV pressure and diastolic dysfunction. Sympathetic activation, decreased parasympathetic tone, and inflammation associated with intermittent hypoxia might contribute to atrial structural and electrical remodeling. 


\section{Review articles}

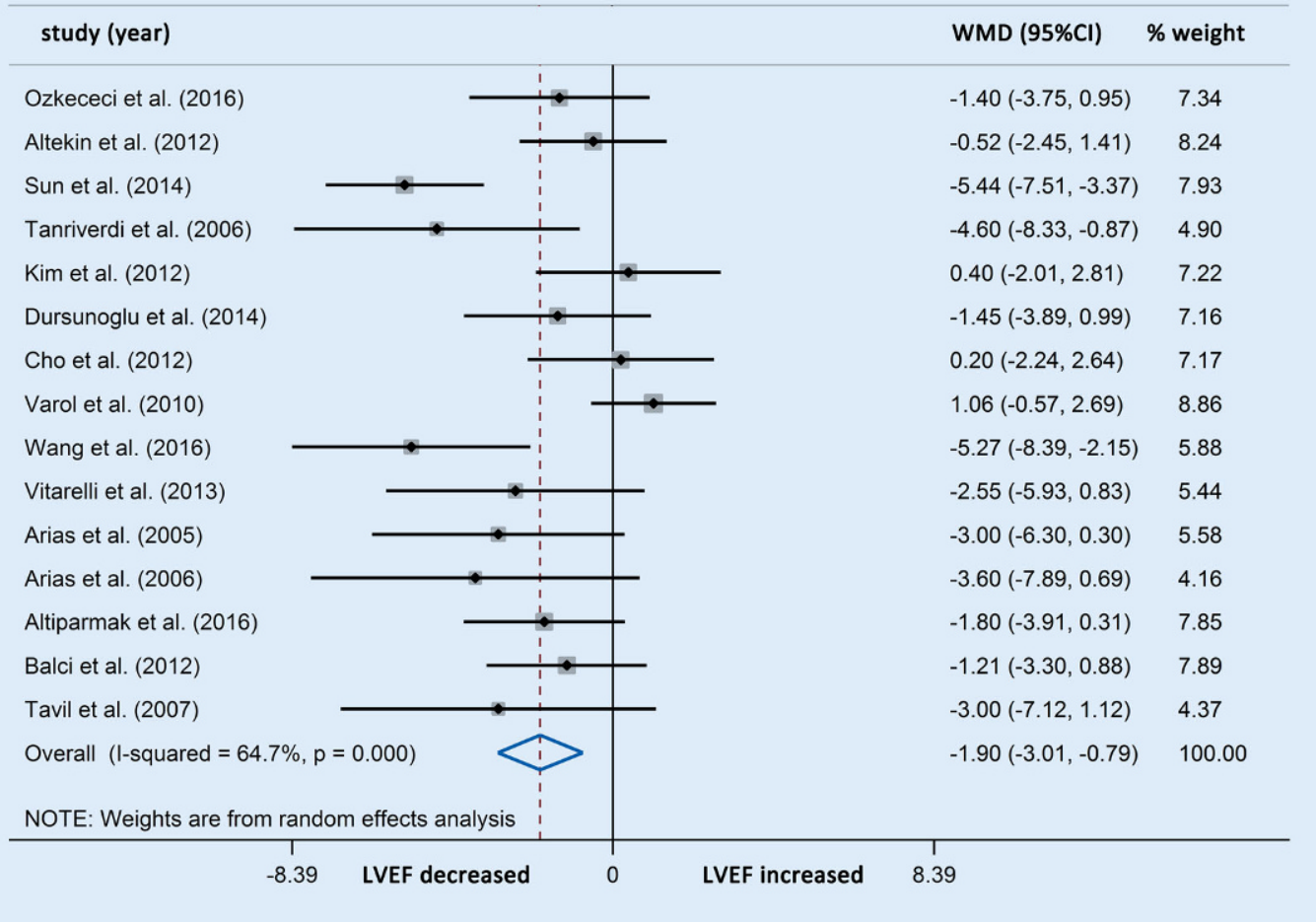

Fig. $6 \triangleleft$ Forest plot of the differences in left ventricular ejection fraction (LVEF) between patients with obstructive sleep apnea syndrome and healthy controls based on echocardiography. WMD weighted mean difference

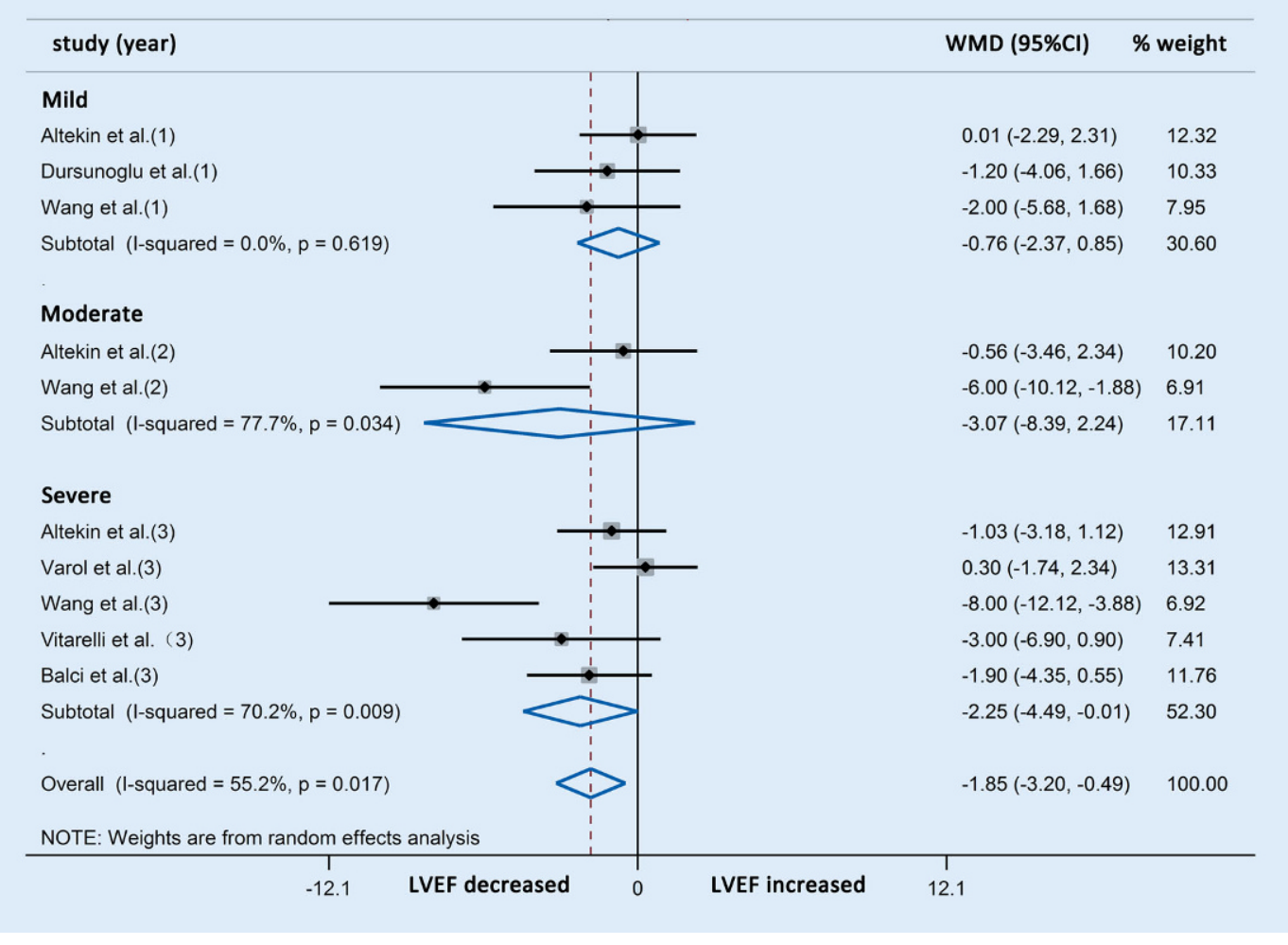

Fig. $7 \triangleleft$ Forest plot of the differences in left ventricular ejection fraction (LVEF) between patients with obstructive sleep apnea syndrome and healthy controls based on echocardiography (subgroup analysis). WMD weighted mean difference 


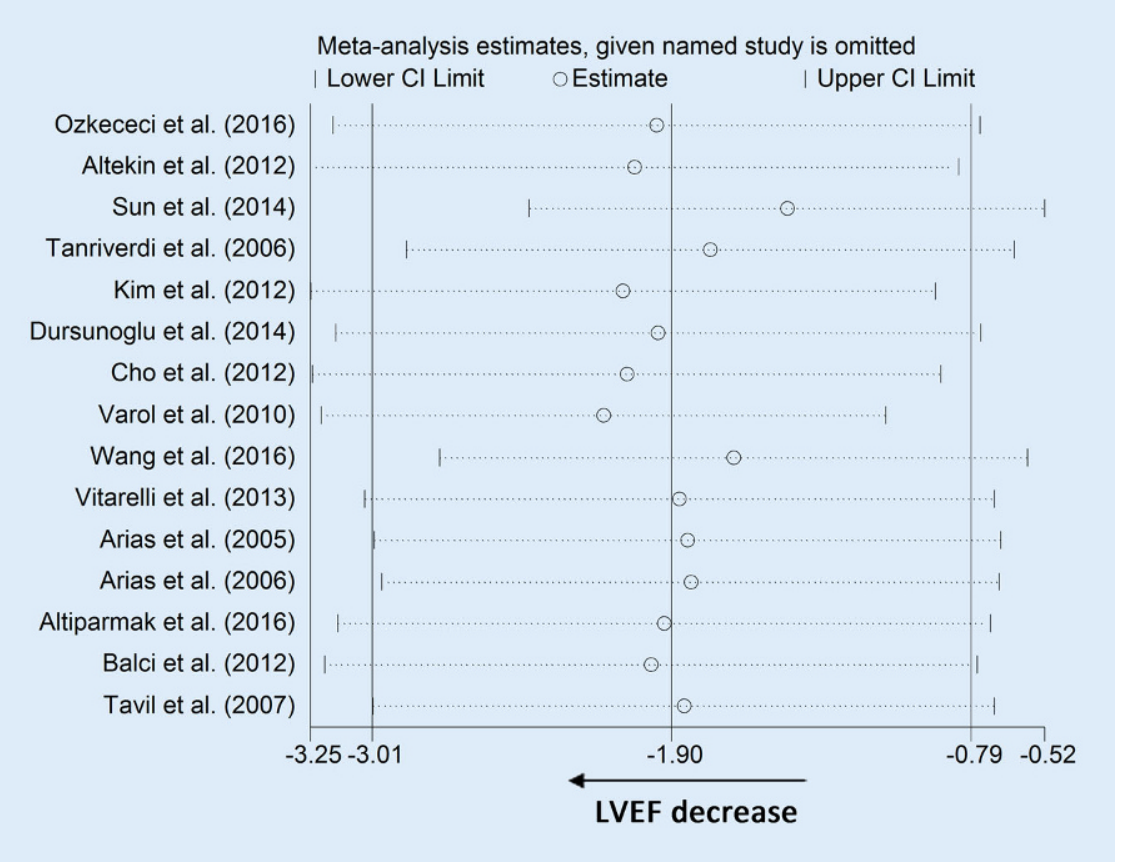

Fig. 8 ॥ Sensitivity analyses of left ventricular ejection fraction (LVEF). Cl confidence interval

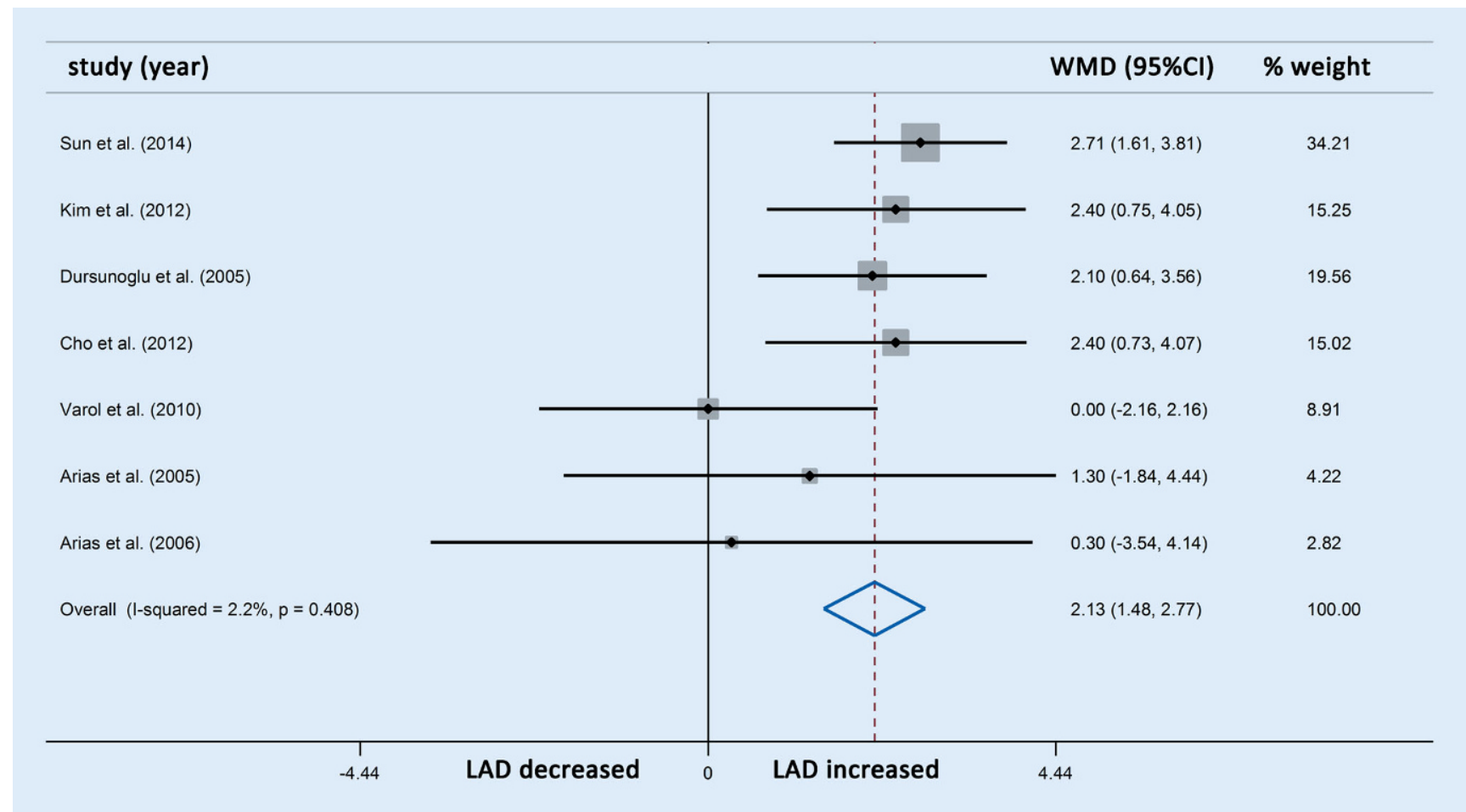

Fig. $9 \Delta$ Forest plot of the differences in left atrial diameter $(L A D)$ between patients with obstructive sleep apnea syndrome and healthy controls based on echocardiography. WMD weighted mean difference 


\section{Review articles}

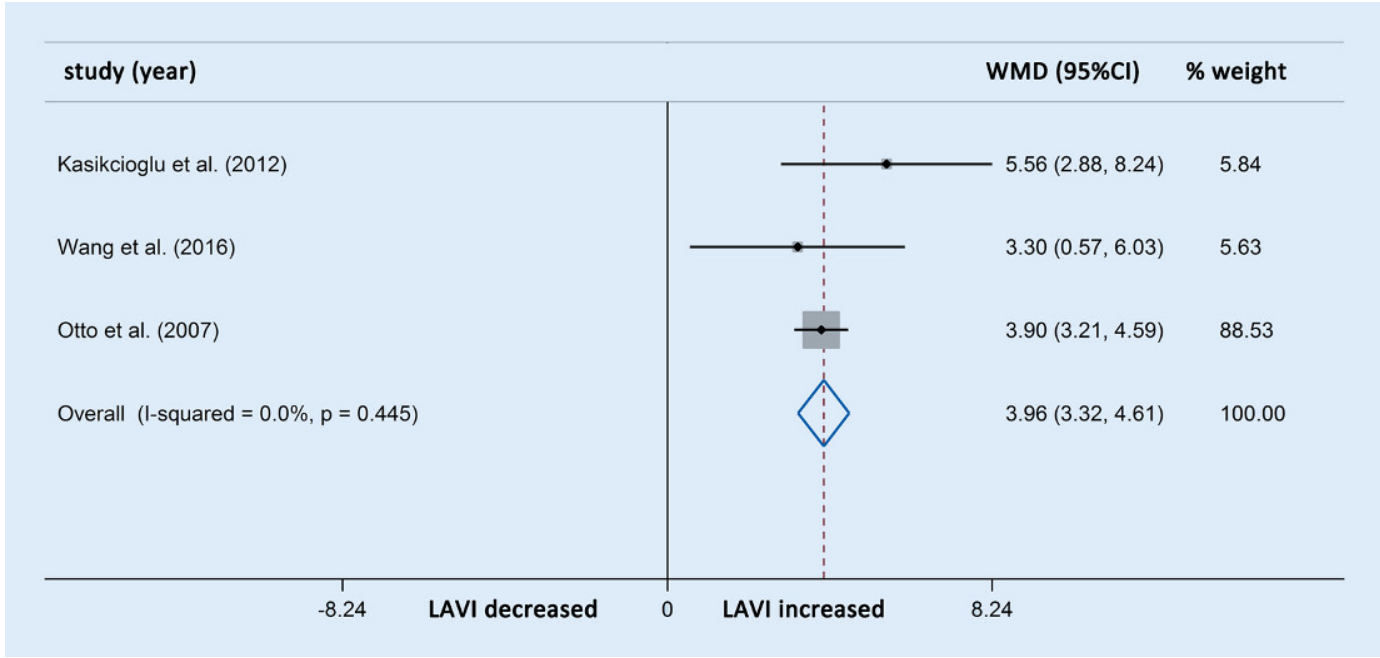

Fig. $10<$ Forest plot of the differences in left atrial diameter volume index (LAVI) between patients obstructive sleep apnea syndrome and healthy controls based on echocardiography. WMD weighted mean difference

It should be noted that recent evidence has indicated OSAS patients might be predisposed to the development and recurrence of atrial fibrillation [48]. The forced inspiration-induced acute LA dilation related to diastolic dysfunction may be an important component of the arrhythmogenic substrate for atrial fibrillation during sleep apnea episodes [9, 25]. More explorations of treatment for OSAS, such as CPAP, are expected to alter the anticipated frequency of OSASrelated cardiac arrhythmias.

\section{RV remodeling and dysfunction in OSAS patients}

The correlation between OSAS and right ventricular (RV) remodeling and dysfunction has also raised intense interest from researchers, but the conclusions from various have differed. Yang et al. found the inner diameters and the anterior wall thickness of the RV were increased in patients with severe OSAS and deteriorated as the disease course progressed [55]. Vitarelli et al. reported that RV dilatation and dysfunction were significantly associated with AHI and the severity and frequency of apnea episodes [52]. Similarly, several other studies reported that OSAS patients presented with right cardiac dysfunction $[1,30]$. By contrast, other studies did not reveal any significant changes in RV morphology and function in OSA patients [14, 17].

Several mechanisms were raised to illustrate the potential relationship be- tween OSAS and RV changes. Prior studies suggested that permanent pulmonary hypertension was an important factor. Repetitive nocturnal arterial oxygen desaturation and hypercapnia lead to pulmonary vascular endothelium remodeling and vasoconstriction, thus increasing pulmonary artery pressure [42], leading to RV overload and inducing the release of inflammatory factors. As a result, the compensatory hypertrophic RV gradually presents with dysfunction. However, recent studies pointed out that RV alternations occurred in early stage of OSAS in the absence of pulmonary hypertension $[30,52]$, indicating that pulmonary hypertension was not the only cause. Some other studies reported the intrathoracic negative pressure against an occluded airway increased venous return and volume overload, and consequently expanded and remodeled the RV [1]. Another possible mechanism is that intermittent hypoxia and $\mathrm{CO}_{2}$ retention stimulated central and peripheral chemoreceptors and increased sympathetic nerve activity, which induced RV dysfunction. In addition, LV dysfunction induced by OSAS may also lead to RV dysfunction, since there is a close anatomical association between the two ventricles [35].

Since the effects of OSAS on the LV and RV may be different, we should conduct further analyses to uncover the precise correlation and mechanism between OSAS and RV remodeling and dysfunction.

\section{Limitations}

The present study was a clinical observational study. The follow-up time was not controlled. In our opinion, the duration of OSAS might be a relevant factor when assessing the effect of OSAS on cardiac structure and function, but it is very difficult to assess the duration of OSAS owing the rate of missed diagnoses in the clinic. Besides, this analysis involved no outcome data such as survival rate and risk of cardiovascular events during follow-up. Further research is needed to clarify the effect of OSAS on the longterm prognosis of patients. Additional analyses may identify the correlation and precise mechanisms between OSAS and RV remodeling.

\section{Conclusion}

On the basis of this meta-analysis, we conclude that patients with obstructive sleep apnea syndrome (OSAS) display increased left atrial dilatation and left ventricular (LV) hypertrophy and dilatation, along with impaired LV systolic function. Therefore, more emphasis should be placed on the clinical significance of OSAS in cardiovascular risk. Treatment against OSAS such as continuous positive airway pressure can attenuate sleep apnea and might prevent the decrease in LV ejection fraction in the long term. 


\section{Corresponding address}

\section{Jian'an Wang, MD, PHD}

Department of Cardiology, Second Affiliated

Hospital, Zhejiang University School of

Medicine

310009 Hangzhou, China

wangjianan111@zju.edu.cn

Funding. There was no funding source for this study. The corresponding author had full access to all the data in the study and had final responsibility for the decision to submit for publication.

Author Contribution. Fan Jiaqi and Li Huajun searched the scientific literature. Yu Lei conducted the statistical analyses, participated in data interpretation, drafted the report, and conceived the study. Zhu Qifeng revised the paper.

\section{Compliance with ethical guidelines}

Conflict of interest L. Yu, H. Li, X. Liu, J. Fan, Q. Zhu, J. Li, J. Jiang, and J. Wang declare that they have no competing interests.

For this article no studies with human participants or animals were performed by any of the authors. The current systematic review and meta-analysis was based on previously published studies with the informed consent of participants prior to inclusion.

Open Access. This article is distributed under the terms of the Creative Commons Attribution 4.0 International License (http://creativecommons.org/licenses/by/ 4.0/), which permits unrestricted use, distribution, and reproduction in any medium, provided you give appropriate credit to the original author(s) and the source, provide a link to the Creative Commons license, and indicate if changes were made.

\section{References}

1. Altekin RE, Karakas MS, Yanikoglu A, Ozel D et al (2012) Determination of right ventricular dysfunction using the speckle tracking echocardiography method in patients with obstructive sleep apnea. Cardiol J 19:130-139

2. Altekin RE, Yanikoglu A, Baktir AO et al (2012) Assessment of subclinical left ventricular dysfunction in obstructive sleep apnea patients with speckle tracking echocardiography. Int J Cardiovascular Imaging 28(8):1917-1930

3. Altıparmak IH et al (2016) Relation of elastic properties of pulmonaryartery with left ventricular abnormalities and aortic stiffness in patients with moderate to severe obstructive sleep apnea: A cross-sectional echocardiographic study. Turk Kardiyol Dern Ars 44(4):289-99

4. Arabi Y, Morgan BJ, Goodman B, Puleo DS et al (1999) Daytime blood pressure elevation after nocturnal hypoxia. J Appl Physiol 87:689-698. https://doi.org/10.1152/jappl.1999.87.2.689

5. Arias MA, Garci'a-Ri' F, Alonso-Ferna'ndez A et al (2005) Obstructive Sleep Apnea Syndrome Affects Left Ventricular Diastolic Function. Circulation 112(3):375-383
6. Arias MA, García-Río F, Alonso-Fernández A et al (2006) Pulmonary hypertension in obstructive sleep apnoea: effects of continuous positive airway pressure. Eur Heart J 27(9):1106-1113

7. Arnardottir ES, Bjornsdottir E, Olafsdottir KA, Benediktsdottir B et al (2016) Obstructive sleep apnoea in the general population: highly prevalent but minimal symptoms. Eur Respir J 47:194-202. https://doi.org/10.1183/13993003.01148-2015

8. Balci MM, Arslan U, Firat H et al (2015) Serum Levels of Adipocyte Fatty Acid-Binding Protein Are Independently Associated With Left Ventricular Mass and Myocardial Performance Index in Obstructive Sleep Apnea Syndrome. J Investig Med 60(7):1020-6

9. Baranchuk A, Simpson CS, Redfearn DP, Fitzpatrick M (2008) It's time to wake up! Sleep apnea and cardiac arrhythmias. Europace 10:666-667. https://doi.org/10.1093/europace/eun078

10. Bradley TD, Floras JS (2003) Sleep apnea and heart failure: part l: obstructive sleep apnea. Circulation 107:1671-1678. https://doi.org/10.1161/01.cir. 0000061757.12581 .15

11. Bradley TD, Floras JS (2003) Sleep apnea and heart failure: part II: central sleep apnea. Circulation 107:1822-1826. https://doi.org/10.1161/01.cir. 0000061758.05044 .64

12. Castro-Grattoni AL, Alvarez-Buve $R$, Torres $M$, Farre R et al (2016) Intermittent hypoxiainduced cardiovascular remodeling is reversed by Normoxia in a mouse model of sleep apnea. Chest 149:1400-1408. https://doi.org/10.1016/j.chest. 2015.11.010

13. Cho KI, Kwon JH, Kim SM et al (2012) Impact of Obstructive Sleep Apnea on the Global Myocardia Performance Beyond Obesity. Echocardiography 29(9):1071-1080

14. D'andrea A, Martone F, Liccardo B, Mazza M et al (2016) Acute and chronic effects of Noninvasive ventilation on left and right myocardial function in patients with obstructive sleep apnea syndrome: a speckle tracking Echocardiographic study. Echocardiography 33:1144-1155. https://doi.org/ 10.1111/echo.13225

15. Dematteis M, Julien C, Guillermet C, Sturm N et al (2008) Intermittent hypoxia induces early functional cardiovascular remodeling in mice. Am J Respir Crit Care Med 177:227-235. https://doi. org/10.1164/rccm.200702-2380C

16. Drosos I, Chalikias G, Pavlaki M, Kareli D et al (2016) Differences between perivascular adipose tissue surrounding the heart and the internal mammary artery: possible role for the leptin-inflammationfibrosis-hypoxiaaxis. Clin Res Cardiol 105:887-900. https://doi.org/10.1007/s00392-016-0996-7

17. Dursunoglu N, Dursunoglu D, Kilic M (2005) Impact of obstructive sleep apnea on right ventricular global function: sleep apnea and myocardial performance index. Respiration 72:278-284. https://doi.org/10.1159/000085369

18. Epstein LJ, Kristo D, Jr SP, Friedman N et al (2009) Clinical guideline for the evaluation, management and long-term care of obstructive sleep apnea in adults. JCSM 5:263

19. Feng J, Zhang D, Chen B (2012) Endothelial mechanisms of endothelial dysfunction in patients with obstructive sleep apnea. Sleep Breath 16:283-294. https://doi.org/10.1007/s11325011-0519-8

20. Ferini-Strambi L, Fantini ML, Castronovo $\mathrm{C}$ (2004) Epidemiology of obstructive sleep apnea syndrome. Minerva Med 95:187-202

21. Franklin KA, Sahlin C, Stenlund H, Lindberg E (2013) Sleep apnoea is a common occurrence in females.
Eur Respir J 41:610-615. https://doi.org/10.1183/ 09031936.00212711

22. Grassi G, Seravalle G, Quarti-Trevano F, Mineo $C$ et al (2010) Reinforcement of the adrenergic overdrive in the metabolic syndrome complicated by obstructive sleep apnea. J Hypertens 28:1313-1320. https://doi.org/10.1097/HJH. 0b013e328337a9

23. Heinzer R, Vat S, Marques-Vidal P, Marti-Soler H et al (2015) Prevalence of sleep-disordered breathing in the general population: the HypnoLaus study. Lancet Respir Med 3:310-318. https://doi.org/10. 1016/s2213-2600(15)00043-0

24. lacobellis G, Corradi D, Sharma AM (2005) Epicardial adipose tissue: anatomic, biomolecular and clinical relationships with the heart. Nat Clin Pract Cardiovasc Med 2:536-543. https://doi.org/ 10.1038/ncpcardio0319

25. Iwasaki YK, Shi Y, Benito B, Gillis MA et al (2012) Determinants of atrial fibrillation in an animal model of obesity and acute obstructive sleep apnea. Heart Rhythm 9:1409-1416.e1401. https:// doi.org/10.1016/j.hrthm.2012.03.024

26. Jean-Louis G, Zizi F, Brown D, Ogedegbe G et al (2009) Obstructive sleep apnea and cardiovascular disease: evidence and underlying mechanisms. Minerva Pneumol 48:277-293

27. Kasikcioglu HA, Karasulu L, Durgun E et al (2005) Aortic elastic properties and left ventricular diastolic dysfunction in patients with obstructive sleep apnea. Heart Vessels 20(6):239-244

28. Kim SM, Cho KI, Kwon JH et al (2012) Impact of obstructive sleep apnea on left atrial functional and structural remodeling beyond obesity. J Cardiol 60(6):475-483

29. Kostopoulos K, Alhanatis E, Pampoukas K, Georgiopoulos G et al (2016) CPAP therapy induces favorable short-term changes in epicardial fat thickness and vascular and metabolic markers in apparently healthy subjects with obstructive sleep apnea-hypopnea syndrome (OSAHS). Sleep Breath 20:1-11. https://doi.org/10.1007/s11325-0151236-5

30. Li J, Wang Z, Li Y, Meng Y et al (2016) Assessment of regional right ventricular systolic function in patients with obstructive sleep apnea syndrome using velocity vector imaging. Medicine 95:e4788-e4788. https://doi.org/10.1097/MD. 0000000000004788

31. Lubrano C, Saponara M, Barbaro G, Specchia P et al (2012) Relationships between body fat distribution, epicardial fat and obstructive sleep apnea in obese patients with and without metabolic syndrome. PLoS ONE 7:e47059. https:// doi.org/10.1371/journal.pone.0047059

32. Lymperopoulos A, Rengo G, Koch WJ (2013) Adrenergic nervous system in heart failure: pathophysiology and therapy. Circ Res 113:739-753. https://doi.org/10.1161/circresaha.113.300308

33. Mariani S, Fiore D, Barbaro G, Basciani S et al (2013) Association of epicardial fat thickness with the severity of obstructive sleep apnea in obese patients. International Journal of Cardiology 167:2244-2249. https://doi.org/10.1016/j.ijcard. 2012.06.011

34. Matsumoto C, Hayashi T, Kitada K, Yamashita C et al (2009) Chymase plays an important role in left ventricular remodeling induced by intermittent hypoxia in mice. Hypertension 54:164-171. https://doi.org/10.1161/hypertensionaha.109. 131391

35. Mittal SR, Barar RV, Arora H (2001) Echocardiographic evaluation of left and right ventricular 
function in mild hypertension. Int J Cardiovasc Imaging 17:263-270

36. Otto ME, Belohlavek M, Romero-Corral A et al (2007) Comparison of Cardiac Structural and Functional Changes in Obese Otherwise Healthy Adults With Versus Without Obstructive Sleep Apnea. Am J Cardiol 99(9):1298-302

37. Ozkececi G, UlasliSS, Akci Oetal (2016) Assessment of pulmonary arterial stiffness in obstructive sleep apnea. Int J Cardiovascular Imaging 32(5):799-805

38. Parisi V, Rengo G, Perrone-Filardi P, Pagano G et al (2016) Increased Epicardial adipose tissue volume correlates with cardiac sympathetic Denervation in patients with heart failure. Circ Res. https://doi. org/10.1161/CIRCRESAHA.115.307765

39. Parisi V, Paolillo $S$, Rengo $G$, Formisano $R$ et al (2017) Sleep-disordered breathing and epicardial adipose tissue in patients with heart failure. Nutr Metab Cardiovasc Dis. https://doi.org/10.1016/j. numecd.2017.09.012

40. Perrelli MG, Pagliaro P, Penna C (2011) Ischemia/ reperfusion injury and cardioprotective mechanisms: role of mitochondria and reactive oxygen species. World J Cardiol 3:186-200. https://doi. org/10.4330/wjc.v3.i6.186

41. Phillipson EA (1993) Sleep apnea-a major public health problem. N Engl J Med 328:1271-1273. https://doi.org/10.1056/nejm199304293281712

42. Sajkov D, Mcevoy RD (2009) Obstructive sleep apnea and pulmonary hypertension. Prog Cardiovasc Dis 51:363-370. https://doi.org/10. 1016/j.pcad.2008.06.001

43. Scala O, Paolillo S, Formisano R, Pellegrino T et al (2016) Sleep-disordered breathing, impaired cardiac adrenergic innervation and prognosis in heart failure. Heart. https://doi.org/10.1136/ heartjnl-2015-309215

44. Shochat T, Pillar G (2003) Sleep apnoea in the older adult: Pathophysiology, epidemiology, consequences and management. Drugs Aging 20:551-560. https://doi.org/10.2165/00002512200320080-00001

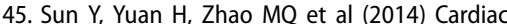
structural and functional changes in old elderly patients with obstructive sleep apnoea-hypopnoea syndrome. JInt Med Res 42(2):395-404

46. Tanriverdi H, Evrengul H, Kaftan A et al (2006) Effect of Obstructive Sleep Apnea on Aortic Elastic Parameters. Circ J 70(6):737-743

47. Tavil Y, Kanbay A, Sen N et al (2007) The Relationship Between Aortic Stiffness and Cardiac Function in Patients with Obstructive Sleep Apnea, Independently from Systemic Hypertension. J Am Soc Echocardiogr 20(4):366-72

48. Todd K, Mcintyre WF, Baranchuk A (2010) Obstructive sleep apnea and atrial fibrillation. NSS 2:39-45. https://doi.org/10.2147/NSS.S7625

49. Trombetta IC, Somers VK, Maki-Nunes C, Drager LF et al (2010) Consequences of comorbid sleep apnea in the metabolic syndrome-implications for cardiovascular risk. Sleep 33:1193-1199. https://doi.org/10.1055/s-0030-1254404

50. Varol E, Akcay S, Ozaydin M et al (2010) Influence of obstructive sleep apnea on left ventricular mass and global function: sleep apnea and myocardial performance index. Heart Vessels 25(5):400-404

51. Vitarelli A, D'Orazio S, Caranci F et al (2013) Left ventricular torsion abnormalities in patients with obstructive sleep apnea syndrome: An early sign of subclinical dysfunction. Int J Cardiol 165(3):512-518

52. Vitarelli A, Terzano C, Saponara M, Gaudio C et al (2015) Assessment of right ventricular function in obstructive sleep apnea syndrome and effects of continuous positive airway pressure therapy: a pilot study. Can J Cardiol 31:823-831. https://doi.org/10.1016/j.cjca.2015.01.029

53. Wang D, Ma GS, Wang XY et al (2016) Left ventricular subclinical dysfunction associated with myocardial deformation changes in obstructive sleep apnea patients estimated by real-time 3D speckle-tracking echocardiography. Sleep Breath 20(1):135-144

54. Xie A, Skatrud JB, Puleo DS, Morgan BJ (2001) Exposure to hypoxia produces long-lasting sympathetic activation in humans. J Appl Physio 91:1555-1562. https://doi.org/10.1152/jappl. 2001.91.4.1555

55. Yang SQ, Han LL, Dong XL, Wang CY et al (2012) Mal-effects of obstructive sleep apnea on the heart. Sleep Breath 16:717-722. https://doi.org/ 10.1007/s11325-011-0566-1

56. Young T, Palta M, Dempsey J, Skatrud J et al (1993) The occurrence of sleep-disordered breathing among middle-aged adults. $\mathrm{N}$ Engl J Med 328:1230-1235. https://doi.org/10.1056/ nejm199304293281704

57. Young T, Peppard PE, Gottlieb DJ (2002) Epidemiology of obstructive sleep apnea: a population health perspective. Am J Respir Crit Care Med 165:1217-1239. https://doi.org/10.1164/rccm. 2109080

\section{DGK Cardio Update 2021 Livestream: Innovativ und flexibel}

19. und 20. Februar aus Mainz 26. und 27. Februar aus Berlin

Umfangreiches Update-Wissen in schwierigen Zeiten: Erstmals können sich interessierte Ärzte für das komplette DGK-Kardiologie-Update-Seminar zum innovativen Livestream anmelden. Seien Sie LIVE dabei, bequem von zu Hause oder aus der Klinik! Die Interaktivität wird durch einen Livechat ermöglicht und die Zertifizierung ist beantragt, sodass Sie auch bei virtueller Teilnahme Ihre wichtigen CME-Punkte erhalten.

Das Update-Konzept: Die wichtigsten Neuerungen des vergangenen Jahres aus der Kardiologie werden unter der wissenschaftlichen Leitung von Prof. Dr. Michael Böhm (Homburg/Saar), Prof. Dr. Stephan Achenbach (Erlangen), Prof. Dr. Ulrich Laufs (Leipzig) und Prof. Dr. Thorsten Lewalter (München) kritisch selektiert, analysiert und zusammengefasst. Die Relevanz für den Klinik- und Praxisalltag der Ärzte steht dabei im Vordergrund und der ausführlichen Diskussion über den Livechat mit den Referenten wird viel Raum gegeben.

In diesem Jahr werden neben den Kerngebieten der Kardiologie die Hot Topics »Herz + Hirn«, »Kritische Fälle und Komplikationen« und »Herz + Psyche» vorgestellt.

Zum Gesamtpaket der Teilnahme gehören, neben den umfangreichen Seminarunterlagen als eBook, der Download aller Vortragspräsentationen und die Vorträge im Nachgang als Video-on-Demand auf der Videoplattform »streamed-up.com«. Weitere Informationen zu Programm Referenten und zur Anmeldung: www.cardio-update.com

Veranstalter: med update $\mathrm{GmbH}$ Hagenauer Straße 53 65203 Wiesbaden 